$\xi=$ 줄

\title{
Preparation and evaluation a new formula of denture cleansers (a comparative study)
}

\author{
Amer A. Taqa ${ }^{1 *}$, Tarik Y. K. Bashi ${ }^{2}$, Safwan M. Al-Aubadi ${ }^{2}$ \\ ${ }^{1}$ DBS. Department, College of Dentistry, University of Mosul, IRAQ \\ ${ }^{2}$ Prosthodontics Department University of Mosul, College of Dentistry, IRAQ \\ *Corresponding author E-mail: amertaqa@hotmail.com
}

\begin{abstract}
The objective of this study is to prepare and study chemical compounds for cleaning denture from locally available materials. The chemical compounds solutions were (sodium bicarbonate with alum), (sodium bicarbonate with citric acid), (sodium bicarbonate with apple vinegar), (sodium bicarbonate with clear commercial vinegar), (sodium bicarbonate with thyme oil), (saturated salt solution), (clear commercial vinegar), (alum). The main study, the effects of the chemical compounds solutions were evaluated on the (color, water Sorption and transverse strength) of heat cured denture base material. The t-test showed that the highest increase in optical density for the specimens immersed in (alum), (sodium bicarbonate +alum), (sodium bicarbonate + apple vinegar) solutions at $1 / 2 \mathrm{hr}$ immersion and it increased more at $8 \mathrm{hrs}$ immersion. The conclusions of this study showed that the safest prepared solutions on the denture base material that could be used as denture cleansers are (sodium bicarbonate $\{7 \mathrm{~g}\}$ with clear commercial vinegar $\{5 \mathrm{ml}\}$ ), (sodium bicarbonate $\{2 \mathrm{~g}\}$ with thyme oil $\{3.57 \mathrm{~g}\}$ ), (saturated salt solution $\{40 \mathrm{~g}\}$ ) at $1 / 2 \mathrm{hr}$ and $8 \mathrm{hrs}$ of immersion. While, (sodium bicarbonate $\{2 \mathrm{~g}\}$ with citric acid $\{4.57 \mathrm{~g}\})$ solution appeared its safety at $1 / 2 \mathrm{hr}$ immersion only.
\end{abstract}

Keywords: Alum; Citric Acid; Denture Cleaner; Saturated Salt; Sodium Carbonate; Vinegar

\section{Introduction}

Acrylic resin is the most employed material in the construction of removable complete and partial denture. This material began to be used since 1930. It is characterized by being strong, having a satisfactory optical property copying the oral tissue appearance, showing low water sorption and solubility and having a good dimensional stability (Anusavice, 1996; Cunningham, 2000). Denture base materials and denture teeth collect the deposits in the same manner as natural teeth (Budtz - Jorgensen et al., 2000; Yeung et al., 2000; Craig et al., 2004). Every surface in the oral cavity, natural synthetic becomes covered within about 30 minute with 0.5 $1.5 \mu$ thick precipitate of salivary glycoprotein and immunoglobulin that is termed "pellicle" (Skjorland et al., 1995; Shay, 2002) The pellicle in turn provides a substrate to which oral debris (mucin, food particles and desquamated epithelial cells and microorganisms "bacteria and fungi" readily adhere (Carlen et al., 1998). So the denture cleanliness is an essential component of oral health to prevent malodor, poor esthetic and accumulation of plaque and Calculus with its deleterious effect on oral mucosal tissue (Dills et al., 1988). Another uneasy cosmetic concern is the stain, which accumulates on the denture surfaces as a result of various habits, namely consumption of colored foodstuff, smoking and drinking beverages (Altman et al., 1979). As such, emphasis must be on the prevention of plaque accumulation with effective plaque removal (Nikawa et al., 1998).

Chemical cleansing approach is recommended for plaque control (Pipko and EL - Sadeek, 1972; Dills et al., 1988; McCabe et al., 1995; Nikawa et al., 1995; Haselden et al., 1998) as an alternative to the mechanical approach in patients with lack of motor coordination (Odman, 1992). Numerous authors have reported the poor hygiene of the complete dentures wearers (Jeganthan et al., 1997, Taqa et.al 2014) because the majority of denture wearers do not receive proper oral hygiene orientation from their dentists. Also the advanced age of the patient leads to a decrease in manual abilities. Knowledge of constituents of denture cleansers, their efficiency, adverse effects and safety are important needs for dental staff so they are able to instruct their patients appropriately (council on dental material and equipment Denture cleanser) (ADA, 1975).

The present study aims to: First; prepare a new formula of compound that can be used as denture cleanser. Second; evaluate the prepared compounds as denture cleansers according to ideal properties of denture cleanser (nontoxic, efficient in tea stain removal, having no adverse effect on the color, water sorption, flexural strength properties of the acrylic resin denture base material at $1 / 2$ and $8 \mathrm{hrs}$ immersion time. Third; compare a new formula with currently used commercial denture cleanser tablets (Unichem, Protefix).

\section{Materials and methods}

The Materials used in this study are Major - Base (type; Heatcuring resin powder and liquid Pink color, Major Prodotti dentari S.P.A Italy), Elite model gypsum (type, 3 model dental stone Zhermack SPA Rovigo, Italy), T.P. Regular (type Modelling wax (Major Prodotti dentari S.P.A, Italy), Isol Major (type Universal separating film, Major Prodotti-Dentari S.R.I Italy). The experimental design of main study: Five hundred twenty eight specimens were prepared from "Major" heat-cured acrylic resin denture base material. The specimens were divided into six groups, each test has two groups as shown in (figure 1). 


\subsection{Preparation of the specimens}

Color and transverse strength specimens Preparation: Wax Specimen Preparation: The specimens were prepared by placing a sheet of wax against a glass slab of $2.5 \mathrm{~mm}$ thickness for transverse strength test and sheet of wax of $1.5 \mathrm{~mm}$ thickness for color property test. The sheets were cut by using a sharp wax knife to the desired length and width for transverse test according to ADA specifications No. 12. While for color test to fit the cuvitte of spectrophotometer in order to obtain an excellent data. The surface of wax was smoothed by piece of tissue nylon type (Hatim and kazanji, 1999). The surface against glass slab was considered the polished surface. The other surface was considered the tissue surface. Flasking, packing, curing, and deflasking was done according to the methods described in the previous studies. (Crispin and Caputo, 1979; Keyf and Etikan, 2004, Anusavice, 1996), then the specimens were stored in distilled water at specified time before each test.
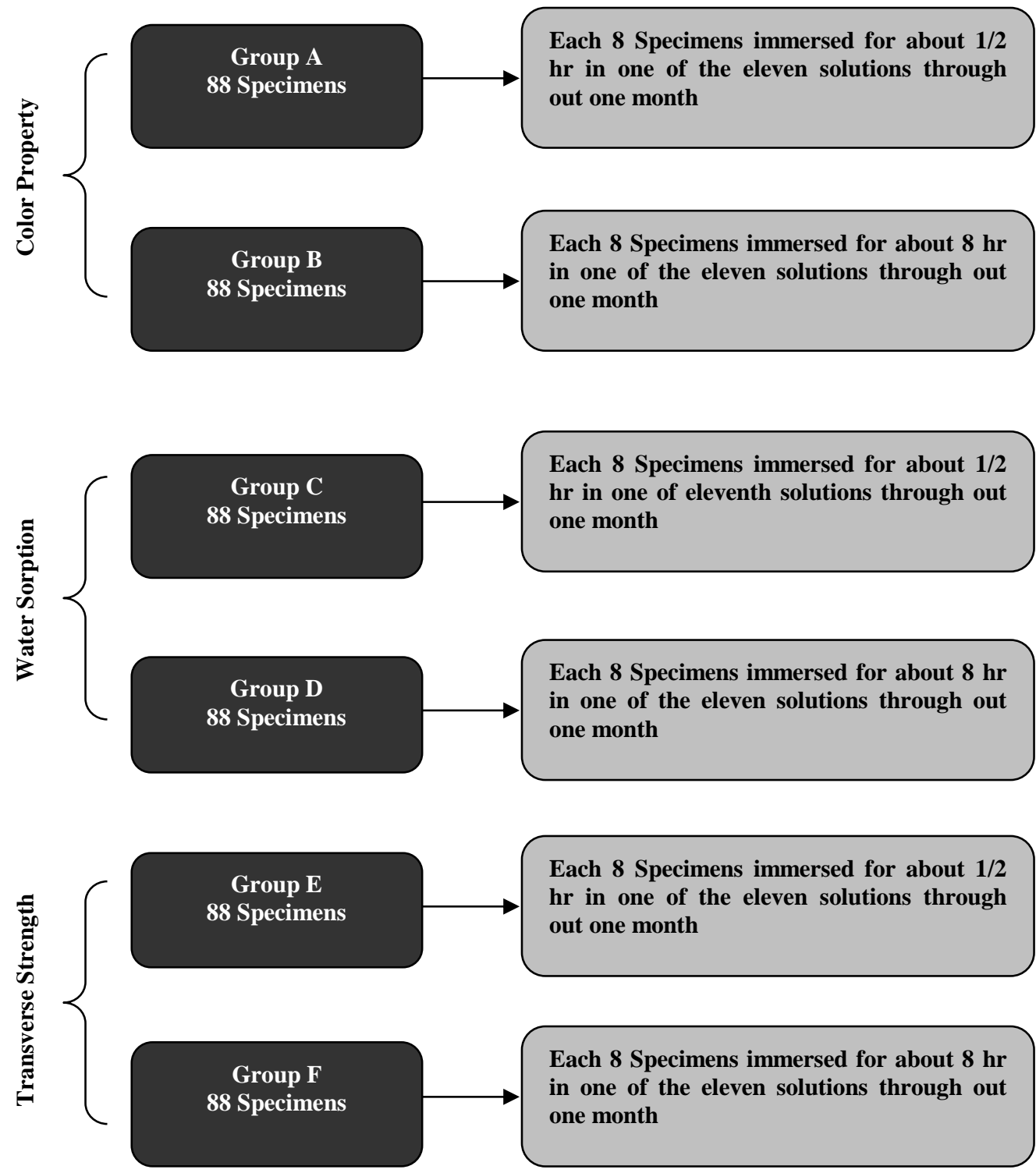

Fig. 1: Denture Base Specimens.

Note: The fresh solutions were prepared daily at the end of soaking trial $(1 / 2 \mathrm{hr}$ and $8 \mathrm{hrs})$. The solutions were removed, the beakers were cleaned and the specimens were immersed in distilled water till the next day, and so on, until it simulates the immersion of 30 days.

\subsection{Preparation of tea solution}

The staining agent (Tea) solution was used in this study to produce artificial staining (In vitro) of specimens because it is a commonly daily consumed beverage. Also it has a strong potential to stain restorative and prosthetic dental materials. Thus it has been used in many studies (Abu - Bakr et al., 2000; Lai et al., 2003; Lee et al., 2005). Eight grams of dry tea were placed in 800 $\mathrm{ml}$ of boiling distilled water for about four minutes and then the tea solution was filtered and allowed to cool to the room tempera- ture. The fresh tea solution was prepared for each treatment (Jagger et al., 2002, Sheen et al., 2002).

\subsection{Procedure of staining}

The optical density was measured for all the specimens before staining with the tea solution "pre-staining measure" by using of Ultraviolet -Visible Spectrophotometer (CECIL). Then the specimens were immersed in the fresh human salvia and then stored in an incubator at $37^{\circ} \mathrm{C}$ for half hour. This will allow the formation of initial pellicle that facilitates the uptake of tea stain (Sheen et al., 2002).Then the specimens were immersed in tea solution and stored in the incubator at $37^{\circ} \mathrm{C}$ for one hour. Then they were removed, washed with distilled water, allowed to air drying. Then the optical density was measured for each specimen. This process has to be repeated until we gain optical density near to (2nm) 
which is considered as the baseline of staining "baseline measure". This process is called stain build up technique (Jagger et al., 2002; Sheen et al., 2002).

\subsection{Water sorption specimens preparation}

A stainless steel die was molded in the lower half of the flask (figure 2). The stainless steel die dimensions were $(50 \pm 1 \mathrm{~mm}$ in diameter and $0.5 \pm 0.05 \mathrm{~mm}$ in thickness). The same procedure was done for packing and curing the major denture base polymer (Crispin and Caputo, 1979; Keyf and Etikan, 2004, Anusavice, 1996). After deflasking the acrylic resin specimens were removed from their stone moulds. Any flashes of excess resin material were removed, then the specimens were numbered and a small hole was prepared in the midline of the upper part for each specimen to allow dispersion by a nylon dental floss in the solutions without contacting each other so that the specimen is surrounded by the solution only (Crispin and Caputo, 1979; Keyf and Etikan, 2004). Then the specimens (figure 3 ) were stored in distilled water at specified time before each test.

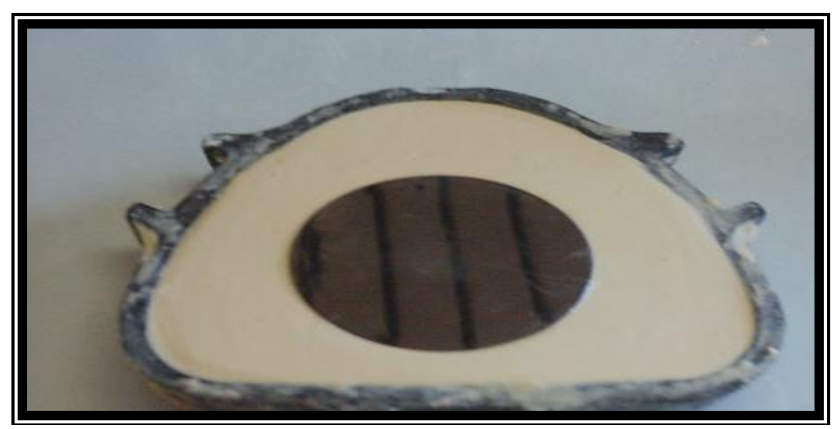

Fig. 2: Water Sorption Die.

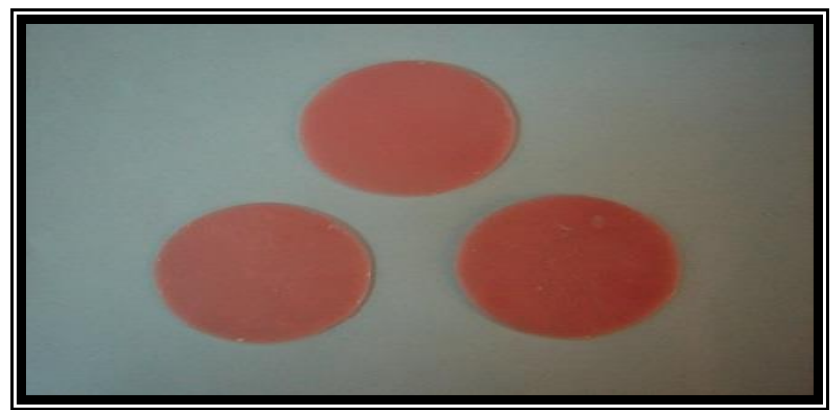

Fig. 3: Water Sorption Specimens

\subsection{Tests used in this study}

The following tests are used to examine the effect of prepared and commercial tablets solutions on three properties of denture base material (color, water sorption and transverse strength).

\subsubsection{Color property test}

Test specimen: Specimens were prepared as described above with dimension of $(45 \times 10 \times 1.5 \pm 0.03 \mathrm{~mm})$ (length, width, and thickness) respectively, in order to fit the cuvitte of the spectrophotometer. The acrylic resin specimens were stored in the distilled water for 7 days at $37^{\circ} \mathrm{C} \pm 1^{\circ} \mathrm{C}$ for conditioning before testing. (Anusavice, 1996).

\subsubsection{Equipment and procedure}

The assessment of color property was done by using ultra violet visible spectrophotometer (CECIL, 2000). The photometric device was used to measure the light transmitted or absorbed with specific material. The absorbed light was measured with accuracy up to 0.001 (Taqa, 2004). The maximum absorption rate for major type heat cured acrylic resin at the wave length $(345 \mathrm{~nm})$, at which the absorbance for each specimens were measured. The specimen was placed in the cuvitte. In such a manner, the radiation source could pass through the middle area of the specimen, and then the absorbed light was measured for each specimen. The transmitted light could be calculated from the following equation: $\mathrm{A}=2-\log \mathrm{T}$ (Parikh, 1974) [A=absorbance, $\mathrm{T}=$ Transmittance]. The optical density for each specimen of the two groups (A, B) was measured before immersion in the solutions. Then the optical density was measured again at the end of one month of immersion in the prepared and tablets solutions to observe the change in color.

\subsection{Water sorption test}

Equipment and Procedure: According to the ADA specification No. 12 the specimens were dried in a desiccator containing freshly dried silica gel at $37^{\circ} \mathrm{C} \pm 2{ }^{\circ} \mathrm{C}$ for $24 \mathrm{hrs}$, then removed to similar desiccator at room temperature for one hour and then weighed on a digital balance. This cycle was repeated until constant weight was attained. The weight loss for each specimen was not more than $0.5 \mathrm{mg}$ in $24 \mathrm{hrs}$ period. This weight was considered as "Conditioned weight ". Then the specimens were immersed in the prepared and tablets solutions according to the study plan. At the end of one month of immersion, They were then removed from the solutions with tweezers, wiped with clean dry hand towel until its became free from visible moisture, waved in air for about $15 \mathrm{sec}-$ onds and weighed on a digital balance (Sartorius, ISO 9001) with a precision of $0.0001 \mathrm{gm}$. The values for water sorption were calculated for each specimen as equation of water sorption (Craig, 1989).

\subsection{Transverse strength test}

Test Specimen: Specimens with dimension of $65 \times 10 \times 2.5 \pm 0.3 \mathrm{~mm}$ (length, width and thickness) respectively, according to ADA specification No.12. The acrylic resin specimens were stored in the distilled water for 7 days at $37^{\circ} \mathrm{C} \pm 1^{\circ} \mathrm{C}$ for conditioning before testing. (Anusavice, 1996).

\subsubsection{Equipment and procedure}

The test was done in air by using 3 points bending on an Instron testing machine. The device was supplied with a central loading plunger and two supports with polished cylindrical surfaces of 3.2 $\mathrm{mm}$ in diameter and $50 \mathrm{~mm}$ between the supports. The supports should be parallel to each other and perpendicular to the central line. The test was carried out with cross head speed of $5 \mathrm{~mm} / \mathrm{min}$. The test specimen was held at each end of the two supports and the loading plunger was placed midway between he supports. The specimens were deflected until fracture occurred. The transverse strength was calculated using the equation described in previous studies. (Craig and Ward, 1997). One way analysis of variance was used to assess the significant difference between the groups at $\mathrm{P} \leq 0.05$

\section{Results}

\subsection{Assessment of the color change of acrylic resin den- ture base}

\subsubsection{Immersion time (1/2 hr)}

The results of the t- test showed in table (1) indicate that there is no significant difference in the optical density of the acrylic resin specimens before and after immersion in the following solutions $(4,5,6,7$, and 9), while the acrylic resin specimens that immersed in the following solutions $(1,2,3,8,10,11)$ show significant differences in their optical densities before and after the immersion. 
Table 1: T - Test of the Optical Density for the Specimens before and After (1/2 Hr) Immersion

\begin{tabular}{llllll}
\hline & Solutions & $\begin{array}{l}\text { Difference of } \\
\text { means }\end{array}$ & $\begin{array}{l}\mathrm{T}- \\
\text { value }\end{array}$ & $\begin{array}{l}\mathrm{P}- \\
\text { value }\end{array}$ & $\mathrm{N}$ \\
\hline 1 & Soda + Alum & +0.040 & 3.930 & $0.006^{*}$ & 8 \\
2 & Soda + citric Acid & -0.040 & 2.779 & $0.027^{*}$ & 8 \\
3 & $\begin{array}{l}\text { Soda + apple } \\
\text { vinegar }\end{array}$ & +0.030 & 4.583 & $0.003^{*}$ & 8 \\
& Soda + clear & -0.030 & 2.016 & 0.084 & 8 \\
5 & vinegar & -0.006 & 0.365 & 0.726 & 8 \\
5 & Soda + thymol oil & -0.020 & 1.578 & 0.159 & 8 \\
6 & Saturated salt & -0.030 & 1.655 & 0.142 & 8 \\
7 & Clear vinegar & +0.090 & 10.926 & $0.000^{*}$ & 8 \\
8 & Alum & -0.014 & 0.599 & 0.568 & 8 \\
9 & Distal Water & -0.060 & 15.875 & $0.000^{*}$ & 8 \\
10 & Unichem & -0.042 & 3.930 & $0.006^{*}$ & 8 \\
11 & Protefix & \multicolumn{3}{c}{ in optical density, + }
\end{tabular}
Increase in optical density.

\subsubsection{Immersion time ( $8 \mathrm{hrs})$}

Table (2) reveal that there is a significant difference in the optical density of the acrylic resin specimens after immersion in all solutions of the study. Also they showed the effect of the prepared solutions on the color at $1 / 2$ and $8 \mathrm{hrs}$ immersion.

Table 2: $\mathrm{T}$ - Test of the Optical Density for the Specimens before and after (8 Hrs) Immersion

\begin{tabular}{llllll}
\hline & Solutions & $\begin{array}{l}\text { Difference of } \\
\text { means }\end{array}$ & $\begin{array}{l}\mathrm{T}- \\
\text { value }\end{array}$ & $\begin{array}{l}\mathrm{P}- \\
\text { value }\end{array}$ & $\mathrm{N}$ \\
\hline 1 & Soda + Alum & +0.100 & 9.504 & $0.000^{*}$ & 8 \\
2 & Soda + citric Acid & -0.060 & 11.225 & $0.000^{*}$ & 8 \\
3 & $\begin{array}{l}\text { Soda+apple vine- } \\
\text { gar }\end{array}$ & +0.060 & 12.000 & $0.000^{*}$ & 8 \\
& Soda+ clear vine- & -0.060 & & & \\
4 & gar & -0.050 & 3.483 & $0.000^{*}$ & 8 \\
5 & Soda + thymol oil & -669 & $0.008^{*}$ & 8 \\
6 & Saturated salt & -0.050 & 2.853 & $0.025^{*}$ & 8 \\
7 & Clear vinegar & -0.070 & 5.857 & $0.001^{*}$ & 8 \\
8 & Alum & +0.160 & 19.423 & $0.000^{*}$ & 8 \\
9 & Distal Water & -0.040 & 4.073 & $0.005^{*}$ & 8 \\
10 & Unichem & -0.170 & 25.968 & $0.000^{*}$ & 8 \\
11 & Protefix & -0.080 & 10.267 & $0.000^{*}$ & 8 \\
\hline
\end{tabular}

Df $=7, *$ Significant difference at $\mathrm{P} \leq 0.05$. - Decrease in optical density, + Increase in optical density.

\subsection{Assessment of water sorption of acrylic resin den- ture base}

\subsubsection{Immersion time $(1 / 2 \mathrm{hr})$}

The means and standard deviations of the water sorption in $\left(\mathrm{mg} / \mathrm{cm}^{2}\right)$ for the acrylic resin specimens immersed in differen tested solutions are shown in Table (3). They showed that the highest water sorption was $\left(0.7400 \mathrm{mg} / \mathrm{cm}^{2}\right)$ for the acrylic resin specimens immersed in (Alum) solution. While the specimens immersed in (Distal water) showed the lowest water sorption $(0.60$ $\mathrm{mg} / \mathrm{cm})$.

\subsubsection{Immersion Time ( 8 hrs)}

The means and standard deviations of the water sorption in $\left(\mathrm{mg} / \mathrm{cm}^{2}\right)$ for the acrylic resin specimens immersed in different tested solutions are shown in Table (4). They revealed that the highest value of water sorption was $\left(0.80 \mathrm{mg} / \mathrm{cm}^{2}\right)$ for the acrylic resin specimens immersed in (Alum) solution, while the lowest value was $\left(0.60 \mathrm{mg} / \mathrm{cm}^{2}\right)$ for the specimens immersed in (Distal water).
Table 3: Means and Standard Deviations of the Water Sorption $\left(\mathrm{Mg} / \mathrm{Cm}^{2}\right)$ for the Specimens Immersed $(1 / 2 \mathrm{Hr})$ in Different Tested Solutions

\begin{tabular}{lllll}
\hline & Solutions & Mean & S.D & N \\
\hline 1 & Soda+ Alum & 0.71 & 0.02563 & 8 \\
2 & Soda + citric Acid & 0.69 & 0.03162 & 8 \\
3 & Soda + apple vinegar & 0.66 & 0.02000 & 8 \\
4 & Soda + clear vinegar & 0.64 & 0.02878 & 8 \\
5 & Soda + Thymol oil & 0.65 & 0.02619 & 8 \\
6 & Saturated salt & 0.61 & 0.02000 & 8 \\
7 & Clear vinegar & 0.73 & 0.02878 & 8 \\
8 & Alum & 0.74 & 0.02268 & 8 \\
9 & Distal Water & 0.60 & 0.02000 & 8 \\
10 & Unichem & 0.67 & 0.02878 & 8 \\
11 & Protefix & 0.63 & 0.02726 & 8 \\
\hline
\end{tabular}

Table 4: Means and Standard Deviations of the Water Sorption for the Specimens Immersed (8 Hrs) in Different Tested Solutions

\begin{tabular}{lllll}
\hline & Solutions & Mean & SD & N \\
\hline 1 & Soda+ Alum & 0.73 & 0.02878 & 8 \\
2 & Soda + citric Acid & 0.71 & 0.02000 & 8 \\
3 & Soda + apple vinegar & 0.68 & 0.03586 & 8 \\
4 & Soda + clear vinegar & 0.65 & 0.02879 & 8 \\
5 & Soda + Thymol oil & 0.67 & 0.02001 & 8 \\
6 & Saturated salt & 0.62 & 0.02887 & 8 \\
7 & Clear vinegar & 0.76 & 0.02726 & 8 \\
8 & Alum & 0.80 & 0.02449 & 8 \\
9 & Distal Water & 0.60 & 0.02978 & 8 \\
10 & Unichem & 0.69 & 0.02888 & 8 \\
11 & Protefix & 0.64 & 0.02010 & 8 \\
\hline
\end{tabular}

\subsection{Assessment of transverse strength of acrylic resin} denture base

\subsubsection{Immersion time ( $1 / 2 \mathrm{hr})$}

The means and standard deviations of the transverse strength in (MPa) for the acrylic resin specimens immersed in different tested solutions are shown in Table (5).

Table 5: Means and Standard Deviations of the Transverse Strength (Mpa) for the Specimens Immersed (1/2 Hr) in Different Tested Solutions

\begin{tabular}{lllll}
\hline & Solutions & Mean & SD & N \\
\hline 1 & Soda+ Alum & 79.76 & 2.05 & 8 \\
2 & Soda + citric Acid & 79.94 & 1.58 & 8 \\
3 & Soda + apple vinegar & 80.66 & 1.75 & 8 \\
4 & Soda + clear vinegar & 81.15 & 1.18 & 8 \\
5 & Soda + Thymol oil & 81 & 1.68 & 8 \\
6 & Saturated salt & 81.68 & 1.22 & 8 \\
7 & Clear vinegar & 79.58 & 2.22 & 8 \\
8 & Alum & 79.08 & 1.57 & 8 \\
9 & Distal Water & 81.86 & 2.48 & 8 \\
10 & Unichem & 80.06 & 1.60 & 8 \\
11 & Protefix & 81.57 & 1.65 & 8 \\
\hline
\end{tabular}

The One Way Analysis of variance (Table 5) show that there is a significant difference $(\mathrm{F}=2.274$ at $\mathrm{P} \leq 0.05)$ in the transverse strength of the acrylic resin specimens immersed in the different tested solutions. The results indicates that the lowest value of transverse strength for the specimens was produced by the (Alum) solution about $(79.08 \mathrm{MPa})$, while the highest value was produced by the (Distal water) which was about $(81.86 \mathrm{MPa})$.

\subsubsection{Immersion time (8 hrs)}

The One Way Analysis of variance (Table 6) demonstrates that there is a highly significant difference $(\mathrm{F}=3.953$ at $\mathrm{P} \leq 0.05)$ in the transverse strength of the acrylic resin specimens immersed in the different tested solutions. 
Table 6: Means and Standard Deviations of the Transverse Strength (Mpa) for the Specimens Immersed (8 Hrs) in Different Tested Solutions

\begin{tabular}{lllll}
\hline & Solutions & Mean & SD & N \\
\hline 1 & Soda+ Alum & 78.85 & 1.89 & 8 \\
2 & Soda + citric Acid & 79.35 & 2.16 & 8 \\
3 & Soda + apple vinegar & 79.96 & 1.84 & 8 \\
4 & Soda + clear vinegar & 80.65 & 1.63 & 8 \\
5 & Soda + Thymol oil & 80.20 & 1.50 & 8 \\
6 & Saturated salt & 81.02 & 1.98 & 8 \\
7 & Clear vinegar & 78.50 & 1.64 & 8 \\
8 & Alum & 77.30 & 1.77 & 8 \\
9 & Distal Water & 82.00 & 2.50 & 8 \\
10 & Unichem & 79.71 & 1.87 & 8 \\
11 & Protefix & 80.90 & 1.63 & 8 \\
\hline
\end{tabular}

The results indicate that the lowest value of transverse strength for the acrylic resin specimens was produced by the (Alum) solution about (77.3 MPa), while the highest value was produced by the (Distal water) which was about (82 MPa).

\section{Discussion}

\subsection{Assessment of the optical density of the denture base material}

\subsubsection{Immersion time (1/2 hr)}

Solution No. (1) (Soda + Alum) produced a significant increase in the optical density of the specimens due to the acidic $\mathrm{pH}$ of the solution that leads to an increase of the water sorption value (0.71 $\mathrm{mg} / \mathrm{cm}^{2}$ ) which in turn leads to the deposition or penetration of the colorants constituents of the solution into the acrylic resin specimen (Ortengren et al., 2001). It may also be due to the gelatinous aluminum hydroxide precipitate $\left(\mathrm{AL}(\mathrm{OH})_{3}\right)$ that is formed when add any base to the aqueous solution of aluminum salt. When this precipitate remains for a period of time, it will change to insoluble formula which has a strength of absorbability to the colorants constituents of the solution (Holliday and Chambers, 1980).

Solution No. (2) (Soda + Citric acid) produced a significant decrease in the optical density of the acrylic resin specimens and this decrease is due to the chelation property of the sodium citrate that is produced from the reaction between the citric acid and sodium bicarbonate. This can be illustrated as sodium citrate solution has $\mathrm{pH}$ value close to the neutral which makes it more effective in chelation (removal of the organic and inorganic components of the deposit). Also the neutral $\mathrm{pH}$ is more compatible than the acidic pH (Lenarda et al., 2000). The chelation process will involve removal of colorant substances (pigments) like iron oxide $(\mathrm{FeO})$ of acrylic resin material.

Solution No. (3) (Soda + Apple vinegar) produced a significant increase in the optical density of the acrylic resin specimens. This change in color is due to the staining effect of the pigment of the extracted natural apple vinegar solution and this result agrees with the (Hersek et al., 1999) who state that the PMMA was a hydrophilic material that attracted more water soluble dyes on the surface as a result of the electrostatic charges. Solution No.(4) (soda + clear vinegar), (5) (soda + thymol oil), (6) (saturated salt solution) produced non-significant difference in the optical density of the acrylic resin specimen. Also solution No. (7) (Clear vinegar), the clear vinegar solution has insignificant effect on the color and this result agrees with (Asmussan, 1983) who found that the low $\mathrm{pH}$ of the storage solution had little effect on the color of the acrylic resin material. Solution No. (8) (Alum) produced a significant increase in the optical density of the acrylic resin specimen. This may be due to the fact that when the no aqueous solution of the aluminum salt dissolved in the water the eighth surfaces aluminum ion formed $\left[\mathrm{Al}\left(\mathrm{H}_{2} \mathrm{O}\right)_{6}\right]^{+3}$ (equation no 1). It will then hydrolyze to form $\left(\mathrm{H}_{3} \mathrm{O}\right)^{+}$that gives acidity to the solution:

$2 \mathrm{KAl}\left(\mathrm{SO}_{4}\right)_{2}+12 \mathrm{H}_{2} \mathrm{O} 2\left[\mathrm{Al}\left(\mathrm{H}_{2} \mathrm{O}\right)_{6}\right]^{+3}+\mathrm{K}_{2} \mathrm{SO}_{4}$
The high acidity of the solution leads to an increase in water sorption and this in turn leads to precipitation of the colorants constituent of the alum solution. Solutions No. $(10,11)$ (Unichem, Protefix tablets) produced a significant decrease in the optical density of the acrylic resin specimen and this may be related to the following causes: first: The chelation property of the sodium citrate that results from the reaction between the citric acid and sodium bicarbonate. Second: Sodium per borate $\mathrm{NaBO}_{2} \cdot \mathrm{H}_{2} \mathrm{O}_{2} \cdot 3 \mathrm{H}_{2} \mathrm{O}$ that contains the bleaching agent $\left(\mathrm{H}_{2} \mathrm{O}_{2}\right)$ which dissociates when it comes in contact with water to release a free radical of $\left(\mathrm{O}_{2}\right)$ which has a strong oxidizing property and is considered as an active factor in cleaning process. This result agrees with (Ma et al., 1997) who reported that heat cured acrylic resin specimens became lighter in color after 7 days of immersion in hydrogen peroxide solution. Third: The decrease in optical density may be due to the effect of the detergent component of the tablet (sodium lauryl sulfate).

\subsubsection{Immersion time (8 hrs)}

The effect of the solutions on the optical density of the acrylic resin specimen has the same sequence as at $1 / 2 \mathrm{hr}$ immersion time but it was large in magnitude, except for the solution no. (4) (Soda + Clear vinegar) that produced a significant decrease in optical density. This may be due to the chelation activity of the sodium acetate that is formed from the reaction of clear vinegar with sodium bicarbonate. Sodium acetate has one carboxyl group that make its chelation activity less than that of sodium citrate which has three carboxyl groups.

\subsection{Assessment of the water sorption of denture base material}

\subsubsection{Immersion time ( $1 / 2 \mathrm{hr})$}

The water sorption values for the specimens immersed in the following solutions $(2,3,4,5,6,10$, and 11) were within the ADA specification limit. Solution No. (1) (Soda + alum): The water sorption value was $\left(0.71 \mathrm{mg} / \mathrm{cm}^{2}\right)$. This value was slightly above the ADA specification limit and this may be due to the following causes: first: The acidic $\mathrm{pH}$ of the solution leads to an increase in the diffusion rate of the water into the acrylic resin specimen (Ortengren et al., 2001).second: The formation of the gelatinous aluminum hydroxide that has high absorbability rate (Holliday and Chambers 1980). Solution No. (7) (Clear vinegar): Vinegar is considered as acidic solvent. This property of the solution leads to the softening of the surface layer of acrylic resin material and decreases inter chain forces and this will allow the water molecules to penetrate the material. Solution No. (8) (Alum) has a low $\mathrm{pH}$ value (3.2), so it behaves as a strong acid solution that increases the water sorption out of the ADA specification limit. This result agrees with (Ortengren et al., 2001) who found that water sorption for three types of composite resins increases at $\mathrm{pH} 4,6$ with increase in storage time.

\subsubsection{Immersion time (8 hrs)}

Water sorption value for the specimens immersed in the following solutions $(3,4,5,6,10,11)$ is still within the ADA specification limit, while the water sorption value for the specimen immersed in the following solutions $(1,7,8)$ is out of the ADA specification limit. The specimens immersed in the solution No (2) (Soda + Citric acid) showed water sorption value out of the ADA specification limit. This may be due to the increase in storage time, which means that the longer exposure of the acrylic resin surfaces to the strong chelating activity of the sodium citrate may lead to roughened acrylic surface which in turn increases and accelerates the water sorption process. This result agrees with (Rahal et al., 2005) who found that the rough surfaces of acrylic resin material increase water sorption and accelerate the rate of water molecule penetration. 


\subsection{Assessment of the transverse strength of the denture base material}

\subsubsection{Immersion time (1/2 hr $)$}

All the tested solutions produced an effect on the transverse strength of the specimens close to the effect of the distal water with slight difference. The lowest values of the transverse strength of acrylic resin specimen produced by the following solutions (Alum + Soda), (Clear vinegar), (Alum) may be due to the acidity of the solutions and its damaging effect on the denture base material. The high acidity of the solution leads to an increase in water sorption and this in turn leads to an increase the plasticizing effect of the penetrated water molecules. Al - Dabagi (2001) found that $5 \%$ of the vinegar solution decreased the transverse strength of the heat cured acrylic specimen through out one week of immersion. $\mathrm{He}$ also found that the vinegar increased the surface roughness of the specimens. Pavarina et al., (2003) found that the 90 days of water immersion period decreased the hardness and transverse strength of the acrylic resin due to the plasticizing action of the water molecules that entered between the chains of the polymer.

\subsubsection{Immersion time (8 hrs)}

The effect of the tested solutions on the transverse strength of acrylic resin specimen still had the same sequence with increase in the magnitude due to the increase of the storage time. The (Alum) solution still has the lowest value, followed by (clear vinegar) solution then followed by (Alum + Soda). Note: The transverse strengths of the acrylic resin specimens immersed in all tested solutions for $1 / 2$ and $8 \mathrm{hrs}$ were still within the ADA specification limit $(60-80 \mathrm{MPa})$.

\section{References}

[1] Abu - Bakr N, Han L, Okamoto A, Iwaku M (2000) Color stability of compomer after immersion in various media. J Esthet Dent; 12: 258 263. http://dx.doi.org/10.1111/j.1708-8240.2000.tb00232.x

[2] Al-Dabagi RKJ (2001) the effect of denture cleansers on transverse strength and deflection of acrylic resin denture base materials. Iraq Dent J.27: $171-184$

[3] Altman MD, Yost KG, Pitts G (1979) A spectrfluorometric protein assay of plaque on dentures and of denture cleaning efficiency .J Prosthet Dent.42:502. http://dx.doi.org/10.1016/0022-3913(79)90242-7.

[4] Amer A Taqa, Ammar Kh Alnori, Hasan Kh Mohialdeen, (2014) the Effect of Newly Prepared Cleansing Agent on the Hardness of High Impact Acrylic Denture Base Material, Adv. Biomed. Pharma. 1:1:15-20.

[5] Amer A. Taqa, Ammar Kh Alnori, Hasan Kh Mohialdeen,(2014) The Effect of Newly Prepared Cleansing Agent on The Surface Roughness and Tensile Strength of Highly Impact Acrylic Denture Base Material. Al- Rafidain Dent J Vol. 14, No1.

[6] Anusavice KJ (1996) Philips science of dental material. $10^{\text {th }}$ ed., Philadelphia, W.B.Saunders Co.pp. 33-47, 211-271.

[7] Asmussen E (1983) Factors affecting the color stability of restorative resin. Acta Odontol Scand 41:11-18. http://dx.doi.org/10.3109/00016358309162298.

[8] Budtz-Jorgensen E, Standerup A, Grabowski M (1975) an epidemiolog ical study of yeast in elderly denture wearers. Community Dental of Oral Epidemiology. 3:115. http://dx.doi.org/10.1111/j.16000528.1975.tb00291.x.

[9] Carlen A, Borjesson AC, Nickdel K (1998) Composition of pellicles formed in vivo on the tooth surfaces in different parts of the dentition and in vitro on hydroxyapatite .Caries Res .32: 447. http://dx.doi.org/10.1159/000016486

[10] Craig RG (1989) Restorative dental materials. $8^{\text {th }}$ Ed .Mosby Co. pp $.519-531$

[11] Craig RG, Power JM, Wataha JC (2004) Dental materials: properties and manipulation. $8^{\text {th }}$ Ed. Mosby Com .pp:124-125, 278.

[12] Craig RG, Ward ML (1997): Restorative Dental Materials. $10^{\text {th }}$ ed. Mosby Co. Pp. 30-52,500 - 551.

[13] Crispin BJ, Caputo AA (1979) Color stability of temporary restorative material. J Prosth Dent; 42(1): 27 - 33. http://dx.doi.org/10.1016/00223913(79)90326-3.

[14] Cunningham JL (2000) Shear bond strength of resin teeth to heat cured and light cured denture base resin. J Oral Rehabil; 27:312-316. http://dx.doi.org/10.1046/j.1365-2842.2000.00522.x.

[15] Dills SS, Olsen AM, Goldner S (1988) Comparison of antimicrobial capability of an abrasive paste and chemical soak denture cleansers. J.
Prosthet. Dent. 60:467. http://dx.doi.org/10.1016/0022-3913(88)90250 $\underline{8}$.

[16] Haselton DR, Diaz-Arnold AM, Dawson DV (2004) Effect of storage solution on surface roughness of provisional crown and fixed partial denture materials. J Prosthodont.13:27-232. http://dx.doi.org/10.1111/j.1532-849x.2004.04039.x.

[17] Hatim NA, Kazanji MN (1999) Effect of some finishing and polishing technique on the degree of roughness of heat cure acrylic surface. Iraqi Dent J. 24:153-168.

[18] Hersek N, Canay S, Uzun G, Yildiz F (1999) Color stability of denture base acrylic resins in three food colorants. J Prosthet Dent. 81:375-9. http://dx.doi.org/10.1016/S0022-3913(99)80001-8.

[19] Holliday AK, Chambers C (1980) The modern inorganic chemistry. Pp: 161-163

[20] Jagger DC, Harrison A, Al-Akhazzami L, Rees JS (2002) the effectiveness of a range of denture cleansers on stain removal from poly methyl methacrylate acrylic resin. Int J Prosthod. 15(6): 549-552.

[21] Jeganthan S, Payne JA, Thean HP (1997) Denture stomatitis in an elderly edentulous Asian population. J. Oral Rehabil. 24:468-472. http://dx.doi.org/10.1046/j.1365-2842.1997.00523.x.

[22] Keyf F, Etikan I (2004) Evaluation of gloss changes of two denture acrylic resin materials in four different beverages. J Dent Mat.20:244251. http://dx.doi.org/10.1016/S0109-5641(03)00099-X.

[23] Lai YL, Lui HF, Lee SY (2003) In vitro color stability, stain resistance and water sorption of four removable gingival flange materials. J Prosthet Dent. 90:293-300. http://dx.doi.org/10.1016/S0022-3913(03)004323.

[24] Lee YK, Lu H, Powers JM (2005) Effect of surface sealent and staining on the fluorescence of resin composites. J. Prosthet. Dent; 93(3): $260-$ 266. http://dx.doi.org/10.1016/j.prosdent.2004.12.017.

[25] Lenarda RD, Cadenaro M, Sbaizero O (2000) Effectiveness of $1 \mathrm{~mol} \mathrm{~L}^{-1}$ Citric acid and $15 \%$ EDTA irrigation on smear layer removal. Int. Endodont J. 33:46-52. http://dx.doi.org/10.1046/j.13652591.2000.00273.x.

[26] Ma T, Johnson GH, Gordon GE, Glenn E (1997): The effect of chemical disinfectants on the surface characteristics and color of denture resin. J. Prosthet. Dent.77: 197-204. http://dx.doi.org/10.1016/S00223913(97)70235-X.

[27] Machado-Silveiro LF, Gonzales-Lopez S, Gonzales UE, Rodriguez MP (2004) Decalcification of root canal dentine by citric acid, EDTA and sodium citrate. Int Endodon J. 37: 365-369. http://dx.doi.org/10.1111/j.1365-2591.2004.00813.x.

[28] McCabe JF, Davidmurry J, Kelly PJ (1995) the efficacy of denture cleansers. Eur J Prosthdont Res Dent. 3(4): 203-207.

[29] Nikawa H,Yamamoto T, Hamada T, Sadomori S (1995) Cleansing efficacy of commercial denture cleansers: ability to reduce Candida albicans biofilm activity. Int J Prosthet. 8:527-534.

[30] Nikawa H, Yamamoto T, Hamada T (1998) Denture plaque, past and recent concerns. J Dent. 26(4):299-304. http://dx.doi.org/10.1016/S0300-5712(97)00026-2.

[31] Odman PA (1992) the effectiveness of enzyme containing denture cleanser.Quint Int J. 23: 187.

[32] Ortengren U, Andersson F, Elgh U, Terselius B, Karlsson S (2001) Influence of $\mathrm{PH}$ and storage time on the sorption and solubility behavior of three composite resin materials. J Dent. 29:35-41. http://dx.doi.org/10.1016/S0300-5712(00)00055-5.

[33] Parikh VM (1974) Absorption spectroscopy of organic molecules. Addison-Welsy Co., pp. 1-43.

[34] Pavarina AC, Machada AL, Giampaldo ET and Vergani CE (2003) Effect of chemical disinfection on transverse strength of denture base acrylic resin. J Oral Rehabil. 30: 1085 - 1089 http://dx.doi.org/10.1046/j.1365-2842.2003.01150.x.

[35] Pipko JD, El-Sadeek M (1972) an in vitro investigation of abrasion and staining of dental resin. J Dent Res. 15: 689-693. http://dx.doi.org/10.1177/00220345720510030201.

[36] Rahal JS, Bramante CM, and Taga EM (2005) Biocompatibility of EDTA, EGTA and Citric Acid .Braz Dent J. 16(1):3-8 http://dx.doi.org/10.1590/S0103-64402005000100001.

[37] Shay K, Ship JA (1995) the importance of oral health in older patient. J AM Geriatr Soc. 43:1414-1422. http://dx.doi.org/10.1111/j.15325415.1995.tb06624.x.

[38] Sheen S, Banfield N, Addy M (2002): The effect of unstimulated and stimulated whole saliva on extrinsic staining in vitro: a developmental method. J Dent. 30: 365-369. http://dx.doi.org/10.1016/S03005712(02)00053-2.

[39] Skjorland KK, Rykke M, Sonju T (1995) Rate of pellicle formation in vivo. Acta Odontol Scand. J. 53:358. http://dx.doi.org/10.3109/00016359509006001.

[40] Yeung AL, Lo EC, Chow TW, Clark KK (2000) Oral health status of patient 5-6 years after placement of cobalt-chromium partial dentures .J Oral Rehabil .27(3):183-189. http://dx.doi.org/10.1046/j.13652842.2000.00512.x. 